this research informs prevention for the development of psychopathology across the life course.

\section{P21 PATTERNS OF BREASTFEEDING AT 3 MONTHS POSTPARTUM IN THE ALBERTA PREGNANCY OUTCOMES AND NUTRITION (APRON) STUDY}

${ }^{1} \mathrm{M}$ Jarman*, ${ }^{2} \mathrm{PJ}$ Robson, ${ }^{3} \mathrm{Y}$ Shen, ${ }^{1} \mathrm{M}$ Madsen, ${ }^{1} \mathrm{RC}$ Bell. ${ }^{1}$ Dept of Agriculture Food and Nutrition Science, University of Alberta, Edmonton, Canada; ${ }^{2}$ Cancer Measurement, Outcomes, Research and Evaluation, Cancer Control Alberta, Alberta Health Services, Edmonton Canada; ${ }^{3}$ School of Public Health, University of Alberta, Edmonton, Canada

\subsection{6/jech-2017-SSMAbstracts.123}

Background Infant feeding is often characterised in broad categories, such as exclusive breastfeeding, partial breastfeeding and formula feeding. However there is little information about detailed patterns of feeding within these groups. The purpose of this study was to examine patterns of breastfeeding from 3 day prospective feeding diaries to describe how women feed their babies.

Methods The APrON study is a prospective study of women during pregnancy and their children. At 3 months postpartum women completed a prospective breastfeeding diary which collected information on the number of feeds, and duration and method of every feed over 3 days. A total of 1080 women completed the breastfeeding diaries.

Results Women reported feeding their babies using combinations of up to 4 different methods (at breast, expressed breastmilk in a bottle, formula, mixed breastmilk and formula in the same bottle) in any one day. For the ongoing analyses women were categorised into 4 groups based on the number and type of feeds reported/day: 1) at breast only $(n=622), 2)$ at breast and expressed breastmilk $(n=223), 3)$ mixed feeding using 2 methods $(n=123)$ and, 4) mixed feeding using 3 or 4 methods $(n=112)$. The proportion of total feeds at breast was $80 \%, 75 \%$ and $64 \%$ for the mothers in the 'at breast and expressed milk', 'mixed feeding using 2 methods' and 'mixed feeding of 3 using 4 methods' groups, respectively. In turn the average daily duration of at breast feeds was longer in women who fed at breast only compared to those in any other method group. Women who fed 'at breast and expressed milk', 'mixed feeding of 2 methods' and 'mixed feeding of 3 or 4 methods' fed, on average, for $18 \mathrm{~min}$, $17 \mathrm{~min}$ and $27 \mathrm{~min}$ less at breast per day, respectively, compared to women who fed at breast only (all $\mathrm{p}=<0.01$ ). There were no differences in the average number of daily feeds between the 4 method groups.

Women use many different combinations of methods within a day to feed their 3 month old babies. Using fewer groups to classify women ignores the 'real life' complexity of feeding patterns. Our data showed that those who used a combination of methods to feed their babies fed had a lower a frequency and total duration of feeding at breast. This could be important to understanding variation in maternal energy expenditure and infant growth, development and health in the future.

In collaboration with the ENRICH team.

\section{P22 CHILDHOOD ADVERSITY, ADULT SOCIOECONOMIC STATUS AND RISK OF WORK DISABILITY - A PROSPECTIVE COHORT STUDY}

${ }^{1} \mathrm{Jl}$ Halonen* ${ }^{*}{ }^{1,2,3} \mathrm{M}$ Kivimäki, ${ }^{4,5} \mathrm{~J}$ Vahtera, ${ }^{3} \mathrm{~J}$ Pentti, ${ }^{1} \mathrm{M}$ Virtanen, ${ }^{1} \mathrm{~J}$ Ervasti, ${ }^{1} \mathrm{~T}$ Oksanen, ${ }^{1} \mathrm{~T}$ Lallukka. ${ }^{1}$ Work Disability Prevention, Finnish Institute of Occupational Health, Helsinki, Finland; '2Department of Epidemiology and Public Health, University College London, London, UK; ${ }^{3}$ Department of Public Health, University of Helsinki, Helsinki, Finland; ${ }^{4}$ Department of Public Health, University of Turku, Turku, Finland; ${ }^{5}$ Turku University Hospital, Turku, Finland

\subsection{6/jech-2017-SSMAbstracts. 124}

Background Employees' health is dependent on individual and social factors operating from across the life course. Studies have shown that negative life events during childhood or low socioeconomic status (SES) in adulthood may predict decreased labour market participation. However, the combined effects of childhood adversities and low SES in adulthood on work disability are not known.

Methods We included 34384 employed Finnish Public Sector study participants who responded to questions about childhood adversities (none versus any adversity, e.g., parental divorce or financial difficulties) in 2008, and whose adult SES (based on occupational status) in 2008 was available. We categorised exposure into four groups: neither (reference), childhood adversity only, low SES only, or both. Participants were followed from 2009 until the first period of register-based work disability (sickness absence $>9$ days or disability pension) due to any cause, musculoskeletal or mental disorders; retirement; death; or end of follow-up (December 2011). We ran cox proportional hazard models adjusted for behavioural, health- and work-related covariates.

Results When compared to those with neither exposure, hazard ratio (HR) for work disability from any cause was increased among participants with childhood adversity, with low SES, and those with both exposures. Low adult SES was a stronger predictor ( $\mathrm{HR} 2.38,95 \% \mathrm{CI}=2.14$ to 2.64 ) of disability due to musculoskeletal disorders than childhood adversity $(1.11,95 \% \mathrm{CI}=1.00$ to 1.23$)$. The difference between the exposures as predictors of disability due to mental disorders was smaller (adversity: $1.40,95 \% \mathrm{CI}=1.23$ to 1.59 ; low SES: $1.21,95 \% \mathrm{CI}=1.03$ to 1.42 ). The highest risk was observed in those with both exposures $(2.53,95 \% \mathrm{CI}=2.29$ to 2.79 for musculoskeletal disability).

Discussion Exposure to adversities in childhood and low SES in adulthood were associated with work disability. Exposure to both these risk factors was associated with the highest work disability risk, although this was additive rather than synergistic effect. Childhood adversity was associated with disability due to mental disorders in particular, whereas low adult SES was more strongly associated with disability due to musculoskeletal disorders.

\section{P23 POSSIBLE IMPLICATIONS OF A PERCEIVED DIVIDE BETWEEN LAY AND OFFICIAL KNOWLEDGE IN AN AREA OF COMPROMISED AND POLLUTED ENVIRONMENT, AND HIGH DEPRIVATION, IN NORTH WEST ENGLAND}

${ }^{1}$ P Elliott*, ${ }^{2} \mathrm{~N}$ Payne. 'Geography, Lancaster University, Lancaster, UK; ${ }^{2}$ School of Health and Related Research, University of Sheffield, Sheffield, UK 